\title{
La nueva regulación y el crédito a la vivienda
}

\author{
Lorena Mullor \\ Asociación Hipotecaria Española \\ Irene Peña \\ Analistas Financieros Internaciones
}

\section{Resumen}

Este artículo analiza el impacto que la nueva regulación ha tenido sobre la financiación a la vivienda. Específicamente, debate dos de las medidas regulatorias más importantes que han sido recientemente aprobadas a nivel europeo. Estas medidas han sido elegidas debido a su relación directa con el mercado hipotecario o como consecuencia de que pueden tener efectos relevantes sobre la actividad crediticia y su disponibilidad. El artículo divide en dos su contenido. La primera parte, profundiza en los nuevos requisitos de capital aplicados a las instituciones crediticias incluido en el paquete regulatorio conocido como «CRD IV». La segunda profundiza en la Directiva adoptada en 2014 que regula el crédito hipotecario, analizando sus principales implicaciones y ajuste en la legislación española.

Palabras clave: vivienda, financiación hipotecaria, regulación, requerimientos de capital, Basel III.

Clasificación JEL: G28, G38.

\begin{abstract}
This paper seeks to analyze the impact that new regulation may have on residential lending. Specifically, it discusses two of the most important regulatory measures recently approved at European level. These regulatory measures have been chosen because of it direct link with residential mortgage lending or because indirectly may affect credit activity and its availability. The work is divided into two parts: the first part focuses on the new capital requirements for credit institutions included in the regulatory package known as «CRD IV». The second focuses on the Directive adopted in 2014 and that regulates mortgage credit, analyzing its main implications and fitting into the Spanish legislation.
\end{abstract}

Keywords: housing, mortgage finance, capital requirement regulation, Basel III.

JEL classification: $G 28, G 38$.

\section{Introducción}

La reciente crisis financiera puso de manifiesto determinados desequilibrios relacionados con la actividad crediticia y el endeudamiento del sector privado. La deuda bancaria fue la base del crecimiento económico del periodo 1992-2007 en Europa y, en países como España con una elevada tasa de vivienda en propiedad, un componente fundamental para garantizar el acceso a la vivienda. 
Esto dio lugar a que el peso del sector financiero sobre la economía europea experimentara un progresivo crecimiento hasta representar 3,1 veces el PIB de la zona euro en 2014 (3,4 en España).

La importancia del sistema financiero y su estrecha relación con el funcionamiento de la economía real, a la luz del impacto que la crisis ha tenido tanto en la evolución del PIB como en los mercados laborales del conjunto de países de la UE, ha provocado una intensa respuesta regulatoria encaminada a asegurar un crecimiento económico más sostenible a largo plazo.

Las reformas legislativas abordadas a nivel europeo afectan a diferentes áreas del sistema financiero desde una óptica global, como en el caso del proyecto de unión bancaria -medida estrella de la anterior Dirección del Mercado Interior de la Comisión Europea (CE)-, pero también específica dirigida a determinados segmentos de actividad, como es el crédito hipotecario.

La importancia de estos cambios hace inevitable una transformación en la composición y el funcionamiento del sistema financiero nacional y europeo. El objeto de este trabajo es, precisamente, analizar el impacto que los principales desarrollos normativos puedan tener en la actividad crediticia y, más concretamente, en el crédito a la vivienda.

En este sentido, del ambicioso paquete legislativo de reformas aprobadas durante 2013 y 2014 analizaremos en detalle, por un lado, la nueva Regulación de los requerimientos de capital y liquidez (capítulo I) y, por otro, la nueva Directiva de crédito hipotecario (capitulo II), intentando desentrañar como normas tan diferentes, que afectan a áreas muy distintas del negocio financiero, pueden tener un impacto directo o indirecto en la actividad crediticia hipotecaria.

Nuestro propósito es explicar no solo cómo el modelo de financiación a la vivienda nacional puede verse influenciado por la normativa europea, sino también cómo hasta la regulación financiera más global, en materia de requerimientos prudenciales, puede incidir en el negocio crediticio minorista más importante en nuestro país: el crédito hipotecario.

\section{La nueva directiva y reglamento de capital y liquidez}

\subsection{Contexto}

El paquete regulatorio conocido como CRD IV, que se desarrolla a través de dos instrumentos legislativos distintos, una directiva y un reglamento, representa la trasposición europea de los nuevos estándares globales en materia de capital bancario propuestos por el Comité de Supervisión Bancaria de Basilea en el documento de reforma de la normativa prudencial bancaria conocida como Basilea III ${ }^{1}$.

La crisis puso de manifiesto algunas de las deficiencias del sector bancario que habían contribuido a exacerbarla y que, entre otras, eran la insuficiencia y mala ca-

\footnotetext{
${ }^{1}$ Publicados el 16 de diciembre de 2010.
} 
lidad del capital en algunas entidades, la falta de reservas de liquidez para hacer frente a situaciones de estrés en el corto plazo o un excesivo apalancamiento.

Por otro lado, el carácter global de la crisis también resaltó la importancia de dar una respuesta global y, especialmente en el contexto de una unión bancaria, de tener una normativa más armonizada que se desarrollara bajo la anterior directiva en materia de capital de 2006.

Por tanto, el amplio paquete de medidas va encaminado a evitar crisis financieras futuras y hacer que el sistema financiero sea menos apalancado y procíclico y, sobre todo, más fuerte: con capital y liquidez suficientes para resistir shocks o situaciones de estrés de los mercados, sea cual sea origen, reduciendo con ello su propagación hacia la economía real.

\subsection{Contenido}

La nueva normativa se aprobó el 16 de abril de 2013 por el pleno del Parlamento europeo y entró en vigor a partir del 1 de enero de 2014. Este paquete consiste en un reglamento [Reglamento (UE) N. 575/2013)] que establece los requisitos prudenciales de las entidades individuales y una directiva (Directiva 2013/36/EU) que regula el acceso a las actividades de captación de depósitos. Ambos suponen el nuevo marco de la regulación bancaria que eventualmente reemplazará a las directivas actuales de requisitos de capital (Directivas 2006/48 y 2006/49).

Si bien los Estados miembros (EEMM) tendrán que trasponer la Directiva a la legislación nacional, el Reglamento es directamente aplicable en los EEMM sin necesidad de trasposición.

El reglamento contiene la regulación de las materias más relevantes: capital, liquidez y apalancamiento. Y establece provisiones detalladas sobre cada una de estas materias, que constituyen un conjunto único de reglas de aplicación en todos los países.

\section{CUADRO 1}

ESTRUCTURA DE LA PROPUESTA

\begin{tabular}{|c|c|}
\hline Directiva & Reglamento \\
\hline $\begin{array}{c}\text { Fuertes vínculos con la legislación nacional, } \\
\text { basado en principios generales }\end{array}$ & $\begin{array}{c}\text { Provisiones detalladas y altamente } \\
\text { prescriptivas que establecen un único conjunto } \\
\text { de reglas }\end{array}$ \\
\hline $\begin{array}{c}\text { Acceso a ocupar / búsqueda de negocios } \\
\text { El ejercicio de la libertad de establecimiento y la } \\
\text { libre circulación de servicios }\end{array}$ & Los requisitos de capital \\
\hline La supervisión prudencial & Ponderaciones de riesgo \\
\hline Buffers de capital / riesgo sistémico buffers & Provisiones de liquidez \\
\hline El gobierno corporativo & Apalancamiento \\
\hline
\end{tabular}

FUENTE: Elaboración propia. 


\subsubsection{Capital}

La crisis financiera ha tenido un coste significativo en Europa, con ayudas públicas por parte de los EEMM destinadas a rescatar al sector estimadas por la Comisión Europea en 2011 -es decir, considerando tan solo los tres primeros años de la crisis- en el entorno de los 1,6 trillones de euros, lo que en términos relativos representaría un 13 por 100 del PIB europeo.

Debido a la magnitud y el carácter imprevisto de estas pérdidas, la Comisión Europea -recogiendo el testigo de Basilea III- ha considerado necesario mejorar la calidad y armonizar los fondos propios que las entidades están obligadas a poseer. Para ello, la normativa establece una nueva definición de los elementos básicos de capital disponibles para absorber las pérdidas imprevistas, cambios en la definición del capital híbrido y una serie de ajustes prudenciales uniformes de los fondos propios.

También se incrementan considerablemente los niveles de fondos propios, fijando, en particular, nuevas ratios de capital que se centran en los elementos básicos de los fondos propios disponibles para absorber pérdidas. Así, el Common Equity Tier I (traducido como capital ordinario de nivel uno y que antes se denominaba «core capital») pasa a ser del 7 por 100 (incluyendo el colchón de conservación, 4,5 + 2,5 por 100), frente al 2 por 100 de Basilea II. Y el capital total (sin incluir el segundo colchón de capital anticíclico de entre el 0-2,5 por 100) asciende al 10,5 por 100 desde el 8 por 100 de la normativa anterior.

El denominador de las ratios de capital son los «activos ponderados por riesgo» (en adelante APR, aunque habitualmente citados por sus siglas en inglés RWA) que son el resultado de ponderar las exposiciones en función de su riesgo de pérdida inesperada. Existen dos métodos de cálculo para los APR: el método estándar (con parámetros determinados por el regulador calibrados para la media del sector e incorporando información externa -ratings-) y el método basado en calificaciones internas o IRB que se divide a su vez en un IRB básico y otro avanzado (ambos basados en parámetros determinados por información interna).

Concretamente, con la nueva regulación las exposiciones garantizadas por hipotecas sobre bienes inmuebles residenciales y comerciales bajo el método estándar tienen una ponderación preferencial armonizada del 35-50 por 100 respectivamente, bajo el cumplimiento de determinadas condiciones. No obstante, las autoridades competentes tendrán que evaluar de manera periódica (al menos anualmente) si estas ponderaciones se basan adecuadamente en el historial de pérdidas de las exposiciones y en las perspectivas futuras de los mercados de inmuebles, pudiendo fijar en cualquier momento una ponderación de riesgo más elevada, de hasta el 150 por 100 .

En el caso del método IRB, se exige a las entidades que faciliten a las autoridades competentes los resultados de aplicar sus modelos internos a unas carteras de referencia elaboradas por la Autoridad Bancaria Europea (en adelante EBA por sus siglas en inglés). Basándose en la información recibida, las autoridades competentes 
tomarán las medidas adecuadas para asegurarse de que las similitudes o las diferencias de los resultados arrojados por una misma exposición estén justificadas en términos de los riesgos afrontados. De forma más general, las autoridades competentes y la EBA deben velar porque la elección entre un método de modelización interno y un método normalizado no conduzca a una infravaloración de los requisitos de fondos propios.

\subsubsection{Liquidez}

La situación de abundante liquidez que caracterizó el ciclo económico previo a la crisis provocó que la anterior normativa prudencial no considerara normas específicas encaminadas a asegurar unas reservas determinadas de liquidez. Sin embargo, durante la reciente crisis se demostró que los valores negociables pueden ser objeto de determinadas presiones que afectan a su liquidez (por ejemplo, como ha ocurrido con las titulizaciones) y es por ello que la nueva normativa trata de evitar la excesiva dependencia de la liquidez del mercado.

Las principales herramientas introducidas para hacer frente a las tensiones de liquidez que puedan aparecer en los mercados a corto y a largo plazo son:

- El requerimiento de cobertura de liquidez (en sus siglas en inglés el LCR), que exige que las entidades acumulen un colchón de activos líquidos de alta calidad para hacer frente a tensiones de liquidez a corto plazo, que se prolonguen durante 30 días. El LCR es el más relevante e inmediato de las ratios y su implementación será gradual: 60 por 100 en 2015, 70 por 100 en 2016, 80 por 100 en 2017 y 100 por 100 en $2018^{2}$.

- Y el requerimiento de financiación estable (NSFR), que exige a las entidades que financien sus activos a largo plazo a través de una composición de instrumentos de financiación estables, tanto en condiciones normales como estresadas. Esta ratio está todavía por definir, y no se producirá hasta 2018.

\subsubsection{Apalancamiento}

El apalancamiento se define como diferencia entre la exposición acumulada de las entidades respecto a sus fondos propios. Como se ha puesto en evidencia durante la crisis, un excesivo endeudamiento puede provocar que únicamente la fortaleza de los fondos propios no sea suficiente para hacer frente a situaciones de tensión. Por eso, en septiembre de 2009, los dirigentes del G-20 se comprometieron a desarrollar normas consensuadas a nivel internacional para desincentivar el apalancamiento excesivo.

\footnotetext{
${ }^{2}$ Un año antes que la ratio definido por BIS III, que entraría en vigor al 100 por 100 en 2019.
} 


$$
\text { Coeficiente de apalancamiento }=\frac{\text { Medida de capital }}{\text { Medida de la exposición }}
$$

Con tal fin se introduce en Basilea III, y se recoge en la CRD IV, una ratio de apalancamiento como medida complementaria del acuerdo marco de Basilea II, definido en términos generales como Capital Tier I entre activos brutos. Esta ratio persigue dos objetivos:

- Por un lado, restringir el excesivo crecimiento de los balances (y así evitar los efectos negativos que tiene el desapalancamiento posterior en las economías).

- Y, por otro lado, ser una medida complementaria a la ratio de capital (antes de la crisis algunos bancos con ratios de capital sólidos mostraban elevados niveles de endeudamiento tanto dentro como fuera de balance). Con esta ratio se intenta evitar que se pueda «jugar» con los activos en función del riesgo.

El coeficiente de apalancamiento no será un requisito vinculante hasta enero de 2018 tras un periodo de observación comprendido entre enero de 2013 y enero de 2017 que permita evaluar la eficacia y el impacto de la ratio sobre los distintos perfiles de riesgo de los modelos de negocio. El seguimiento se realizará en base a las directrices publicadas en 2010 por el Comité de Basilea en las que se proponía (provisionalmente) un coeficiente mínimo de apalancamiento del 3 por 100.

\section{CUADRO 2}

\section{CRONOGRAMA}

\begin{tabular}{|c|c|c|c|c|c|}
\hline $\mathbf{2 0 1 4}$ & $\mathbf{2 0 1 5}$ & $\mathbf{2 0 1 6}$ & $\mathbf{2 0 1 7}$ & $\mathbf{2 0 1 8}$ & $\mathbf{2 0 1 9}$ \\
\hline $\begin{array}{c}\text { Entrada en } \\
\text { vigor del CRR }\end{array}$ & Liquidez & $\begin{array}{c}\text { Límite } \\
\text { trasposición } \\
\text { CRD }\end{array}$ & - & $\begin{array}{c}\text { Apalan- } \\
\text { camiento }\end{array}$ & Capital total \\
\hline
\end{tabular}

FUENTE: Elaboración propia.

\subsection{Análisis de impacto}

El conjunto de medidas introducidas y resumidas en el apartado anterior relacionadas con aspectos de capital, solvencia y endeudamiento vienen a fortalecer los balances de las entidades financieras y a disminuir los riesgos asociados a un excesivo endeudamiento en caso de quiebra de las entidades.

El nivel de exigencia de alguno de los requisitos, como los asociados a los niveles de capital, ha aconsejado un cumplimiento gradual en base a un calendario establecido. Asimismo, algunas de las ratios están sujetas a revisión ante la falta de evidencias empíricas sobre el alcance final que puedan tener. 
En todo caso, es previsible que la incorporación total de los requisitos contemplados en la CRD IV, prevista para 2019, tenga efectos en la disponibilidad y precio del crédito.

\subsubsection{Capital}

Los niveles exigidos de capital deberán alcanzarse a partir 2019, no obstante la mayoría de entidades europeas, incluidas las españolas, ya han comenzado el proceso de capitalización. Cabe destacar que la normativa no contempla únicamente un incremento de los niveles de capital, sino que también redefine los instrumentos que se consideran capital regulatorio, incrementando su calidad. Por ejemplo, se revisan los híbridos admisibles en el Tier 1 y Tier 2 y se deducen del capital impuestos diferidos, fondo de comercio y participaciones financieras entre otros.

El cumplimiento con los nuevos criterios de capital va asociado a una pérdida de rentabilidad como consecuencia del incremento de los niveles de fondos propios que tendrá que ser compensada por las entidades a través mejores márgenes en sus segmentos de actividad. Esto puede dar lugar a un encarecimiento del crédito, incluyendo el hipotecario en el que tradicionalmente las entidades han competido en márgenes, ya que el coste de la financiación o funding dependerá de las condiciones de mercado y podría verse afectado, igualmente, por la introducción de otras medidas del paquete regulatorio como las referidas a la liquidez (que promueven el uso de instrumentos de funding más a largo plazo y seguros).

Por otro lado, las ponderaciones preferenciales aplicadas a inmuebles residenciales y comerciales (del 35 pr 100 y 50 por 100 respectivamente) son susceptibles de ser revisadas al alza por los EEMM en función de su historial de pérdidas y las perspectivas futuras de los mercados de bienes inmuebles.

De producirse, esta revisión al alza podría afectar negativamente a la oferta de crédito a la vivienda y encarecerlo. Además, podrían darse efectos procíclicos si la revisión se produce de forma reactiva en momentos de recesión económica y no de manera preventiva ante señales de calentamiento del mercado.

Asimismo, los EEMM pueden considerar, si así lo ven necesario, otros criterios más estrictos para la ponderación preferencial. Estos criterios podrían ir dirigidos a endurecer aspectos relacionados con la relación préstamo valor (LTV en inglés) o préstamo ingresos (LTI); lo que plantea el riesgo de que determinados segmentos de demanda, como es el primer acceso caracterizado por unos menores niveles de ahorro previo y rentas, no pudieran acceder de forma directa a la financiación bancaria. 


\section{GRÁFICO 1 \\ NIVELES DE CAPITAL ORDINARIO DE NIVEL 1 POR PAÍSES \\ (En \%, 2014)}

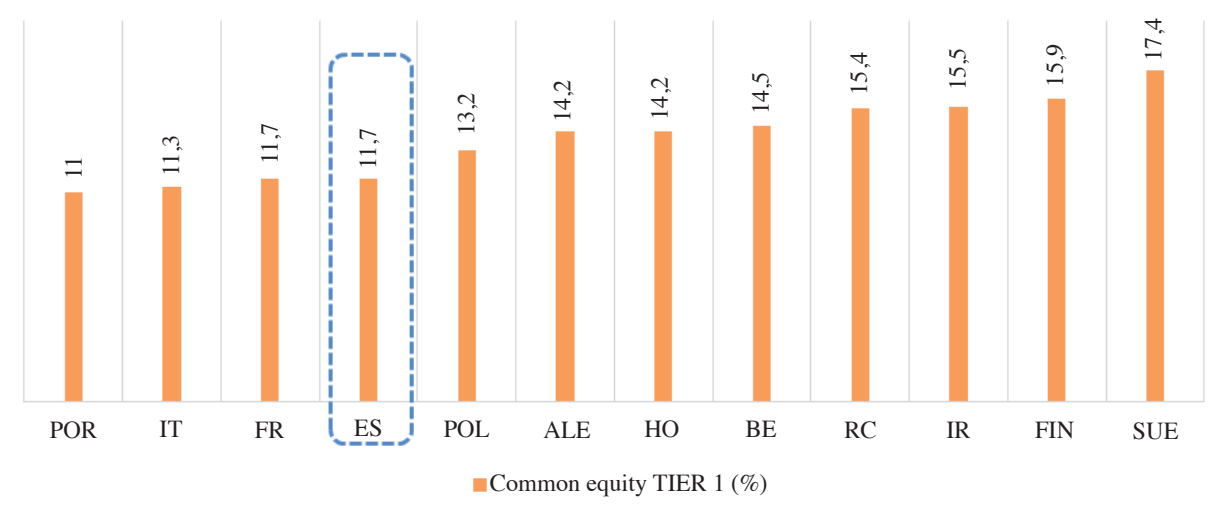

FUENTE: BCE, Analistas Financieros Internacionales.

\subsubsection{Liquidez}

La introducción de medidas de liquidez supone una novedad para la normativa española, que hasta la fecha no contemplaba ninguna referencia a posibles escenarios de riesgo de liquidez.

La primera de las medidas introducidas, el LCR o requerimiento de cobertura de liquidez, conlleva la creación de un colchón de activos líquidos de alta calidad para hacer frente a las tensiones de liquidez a corto plazo.

Su definición final se hizo pública en enero de 2015 con la entrada en vigor del Reglamento Delegado (UE) 2015/61 de la Comisión, e introdujo un cambio significativo y positivo para la actividad hipotecaria respecto a la propuesta de Basilea III al incluir a los bonos garantizados (cédulas hipotecarias) y las titulizaciones como activos líquidos.

La aceptación de estos instrumentos, especialmente de las cédulas hipotecarias, potenciará su uso entre entidades, obligadas a mantener reservas de bonos garantizados emitidos por otras instituciones, generando una nueva demanda para este instrumento que potenciaría la financiación del crédito hipotecario.

Entre los aspectos negativos de la introducción de la ratio, se señala una posible menor disponibilidad de recursos para la actividad crediticia que tendrían que estar reservados en el colchón de liquidez.

En cuanto al NSFR o requerimiento de financiación estable, su introducción podría suponer cambios en el modelo de financiación típico de las entidades de crédito con un peso significativo de los depósitos (a corto plazo). No obstante su implementación no debería afectar de forma directa a la oferta de crédito por parte de las entidades (volumen), si bien indirectamente sí podría afectar a los precios (tipo de interés). 


\section{CUADRO 3}

VARIACIONES ENTRE EL REGLAMENTO RELEGADO DE LA CE DE ENERO DE 2015 Y LA PROPUESTA DE BASILEA DE ENERO DE 2013

\begin{tabular}{|c|c|c|c|c|c|c|c|}
\hline & \multicolumn{3}{|c|}{ Reglamento delegado enero 2015} & \multicolumn{3}{|c|}{ Basilea enero 2013} \\
\hline & & Nivel 1 & Nivel 2A & Nivel 2B & Nivel 1 & Nivel 2A & Nivel 2A \\
\hline \multirow{3}{*}{$\begin{array}{l}\text { Cédulas } \\
\text { (no } \\
\text { retenidas) }\end{array}$} & Inclusión & $\checkmark$ & $\checkmark$ & $\checkmark$ & $x$ & $\checkmark$ & $x$ \\
\hline & $\begin{array}{l}\text { Caracte- } \\
\text { rísticas }\end{array}$ & $\begin{array}{c}\text { Emisiones } \\
\text { superiores } \\
\text { a } 250 \text { mill } \\
\text { con rating } \\
\text { igual o } \\
\text { superior } \\
\text { a A- }\end{array}$ & $\begin{array}{c}\text { Emisiones } \\
\text { superiores } \\
\text { a } 500 \text { mill } \\
\text { con rating } \\
\text { igual o } \\
\text { superior a } \\
\text { AA- }\end{array}$ & $\begin{array}{l}\text { Emisiones } \\
\text { superiores } \\
\text { a } 250 \text { mill }\end{array}$ & & $\begin{array}{c}\text { Rating } \\
\text { igual o } \\
\text { superior a } \\
\text { AA- }\end{array}$ & \\
\hline & Haircut $(\%)$ & $7 \%$ & $15 \%$ & $30 \%$ & & $15 \%$ & \\
\hline \multirow{3}{*}{$\begin{array}{l}\text { Titula- } \\
\text { ciones }\end{array}$} & Inclusión & $x$ & $x$ & $\checkmark$ & $x$ & $x$ & $\checkmark$ \\
\hline & $\begin{array}{c}\text { Caracte- } \\
\text { rísticas }\end{array}$ & & & $\begin{array}{l}\text { RMBS/ } \\
\text { CLOSME } \\
\text { con rating } \\
\text { igual o } \\
\text { superior a } \\
\text { AA- }\end{array}$ & & & $\begin{array}{l}\text { RMBS } \\
\text { con rating } \\
\text { igual o } \\
\text { superior a } \\
\text { AA }\end{array}$ \\
\hline & Haircut $(\%)$ & & & $25 \% / 35 \%$ & & & \\
\hline
\end{tabular}

FUENTE: Analistas Financieros Internacionales.

\subsubsection{Apalancamiento}

Como se ha comentado anteriormente, la ratio de apalancamiento pretende prevenir un endeudamiento excesivo por parte las entidades y ser un complemento a los requisitos de capital.

La definición final de la ratio no será conocida hasta finales de 2017, pero al ser un limitador del crecimiento del activo, se puede prever que una vez esté implementado tenga efectos sobre los niveles de oferta de crédito y, especialmente, sobre el crédito hipotecario, al ser uno de los segmentos de actividad con más peso en el balance de las entidades españolas.

La definición actual de la ratio podría penalizar en mayor medida a determinadas entidades europeas con un modelo especialista de crédito hipotecario -y que, por tanto, están muy apalancadas- mientras que en un modelo de banca universal como el español el impacto podría ser menos significativo. Es por ello que el Reglamento establece la necesidad de evaluar la conveniencia de introducir niveles diferenciados de la ratio para distintos modelos de negocio.

También se establece la necesidad de evaluar el impacto de la ratio en los diferentes modelos de negocio y estructuras de balance de las entidades, especialmente en cuanto a líneas de negocio de bajo riesgo como es la financiación de inmuebles 
residenciales. Esto representaría un cambio positivo de cara a la actividad crediticia, ya que la propuesta de Basilea no contempla la reducción de la medida de la exposición por avales o garantías (como la hipotecaria) que minoren el riesgo de crédito.

\section{GRÁFICO 2 \\ DESGLOSE FINALIDADES DE CRÉDITO POR PAÍSES}

(En \%, 2014)

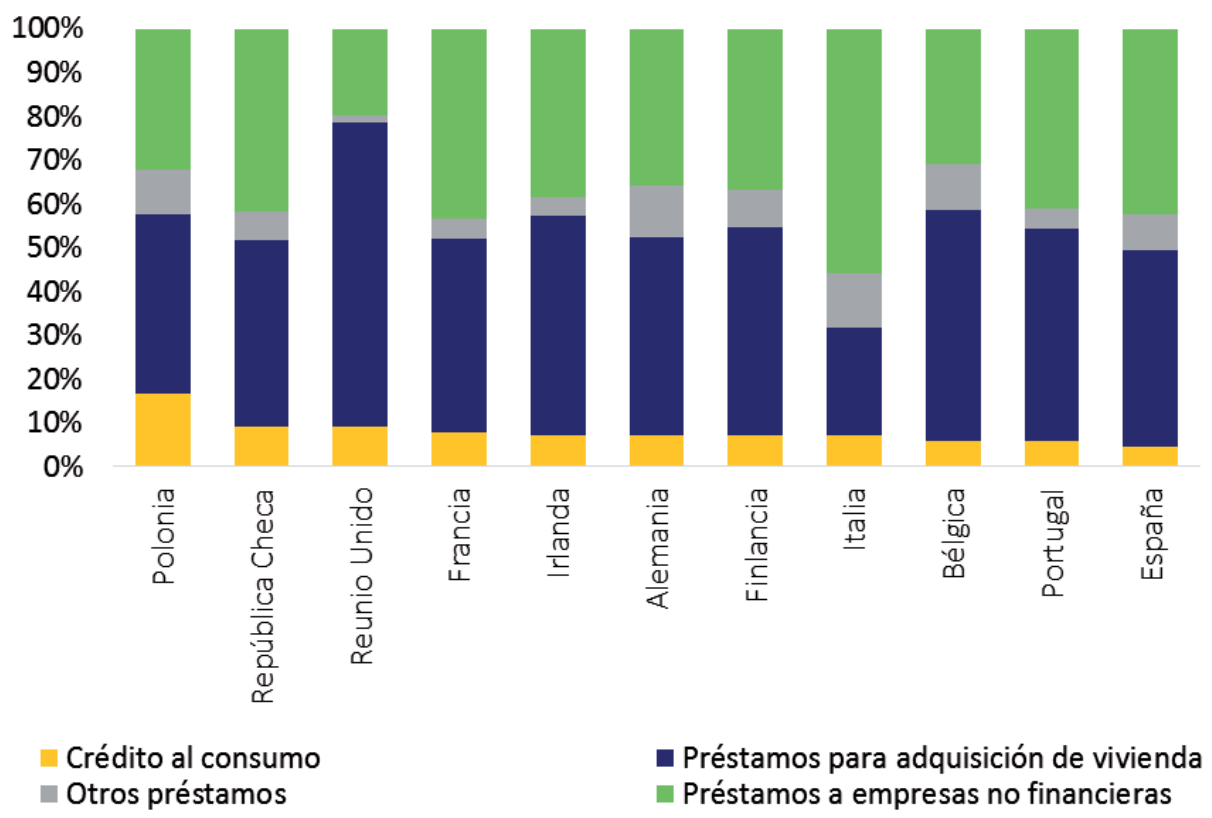

FUENTE: Analistas Financieros Internacionales.

\section{Directiva sobre crédito hipotecario}

\subsection{Contexto}

El 28 de febrero de 2014 se publicó la Directiva que regula el crédito hipotecario en Europa ${ }^{3}$. A partir de esa fecha, los EEMM tienen dos años para trasponer esta Directiva a sus ordenamientos nacionales, es decir, hasta marzo de 2016.

El germen de esta regulación se sitúa en marzo de $2003^{4}$, cuando la Comisión Europea decidió analizar los obstáculos existentes para el desarrollo del crédito

${ }^{3}$ Directiva 2014/17/UE sobre los contratos de crédito celebrados con los consumidores para bienes inmuebles de uso residencial

${ }^{4}$ Año en el que se constituye un grupo de trabajo formado por profesionales del sector -denominado Forum Group sobre Crédito Hipotecario- para analizar los obstáculos a la integración. 
hipotecario transfronterizo y formular recomendaciones para su eliminación. Cabe destacar que los mercados hipotecarios europeos siempre han tenido un carácter acusadamente local, con importantes diferencias entre sí que se derivan, fundamentalmente, de los distintos marcos reguladores, económicos y políticos.

Efectivamente, las condiciones económicas del crédito hipotecario son distintas en cada uno de los mercados; el acceso a la información y a la distribución, que en la mayoría de los mercados se produce a través de una red de sucursales consolidada, constituye una barrera real para los nuevos operadores. Por otra parte, aspectos legales como la constitución de la garantía o los procedimientos de ejecución varían significativamente de un país a otro, así como las políticas fiscales, de supervisión o de protección y transparencia para los consumidores. Todos estos factores han incidido de forma clara tanto en la gama de préstamos ofertados como en la organización del mercado, y por tanto no solo han limitado la creación de un mercado único de hipotecas, sino también el grado de desarrollo de los mercados nacionales.

\section{GRÁFICO 3}

SALDO VIVO DEL CRÉDITO HIPOTECARIO A LOS HOGARES (TOTAL NACIONAL)

Crédito hipotecario hogares

(\% sobre PIB)

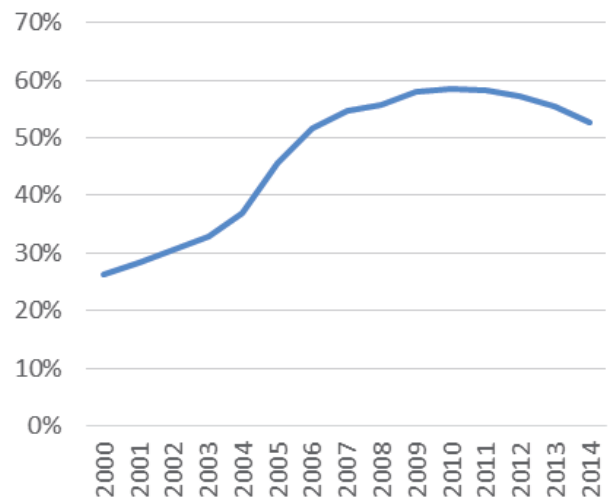

Crédito hipotecario hogares

(€ per capita)

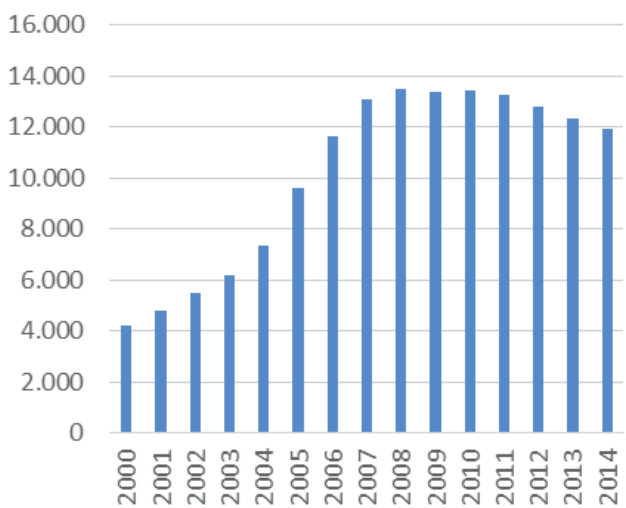

FUENTE: Asociación Hipotecaria Española.

Tras varios años de estudio y consultas al mercado, finalmente en diciembre de 2007 -en un entorno de incipiente crisis financiera- la Comisión Europea publica su Libro blanco sobre la integración de los mercados de crédito hipotecario de la $U E$, en el que se resumen sus diferentes conclusiones y opciones de política, y en el que se incluye un nuevo objetivo de regulación -casi preponderante por encima del resto- en respuesta a la crisis: asegurar el endeudamiento responsable por parte de prestamistas y prestatarios. 
Así pues, con la publicación del libro blanco se da el pistoletazo de salida al proceso regulatorio que finalizó en 2014 con la publicación de esta Directiva, culminando 11 años de análisis del mercado hipotecario europeo.

El objetivo de la nueva norma es doble: por un lado, la creación de un mercado único de créditos hipotecarios que sea eficiente y competitivo; y por otro, garantizar una mayor protección de los consumidores mediante el impulso de prácticas de concesión responsable en el crédito hipotecario.

El impacto de esta Directiva en los mercados hipotecarios europeos va a ser muy significativo en la medida en que altera sustancialmente los procesos de concesión de los préstamos hipotecarios.

\subsection{Contenido}

La nueva norma se aplica a los contratos de crédito garantizados por una hipoteca, o por otra garantía comparable comúnmente utilizada en un Estado miembro, sobre bienes inmuebles residenciales (fincas o edificios construidos o por construir). Se excluyen algunos tipos de préstamos, como por ejemplo la denominada Hipoteca Inversa, y se deja a discreción de cada país la exclusión o no de otro tipo de préstamos, como por ejemplo: los de comprar para alquilar (buy to let), o los préstamos puente.

Las áreas relevantes que regula esta nueva normativa son las siguientes:

\section{a) Educación financiera}

Se incluye un mandato a los EEMM para que promuevan medidas para apoyar la educación de los consumidores en relación tanto al endeudamiento responsable como a la gestión de las deudas.

\section{b) Normas de conducta y conocimientos del prestamista}

La Directiva introduce medidas relacionadas con el comportamiento (responsable) de las entidades de crédito con respecto a sus consumidores, así como recomendaciones sobre la política de remuneración del personal encargado de realizar el análisis de la solvencia del consumidor (cuya retribución deberá no fomentar la toma excesiva de riesgos, ser compatible con los intereses y objetivos a lo largo plazo del prestamista, y no depender del número de las solicitudes aceptadas).

Destaca también la inclusión de diferentes reglas sobre nivel de formación y competencias que debe tener el personal dedicado a la elaboración, la oferta o la concesión de contratos de crédito. 


\section{c) Información}

Se regula la información básica a incluir en los folletos publicitarios y se exige que, en general, la publicidad y marketing sean claras, justas y no generen falsas expectativas sobre la disponibilidad o el coste de crédito.

Además, se introduce nueva regulación sobre la venta vinculada ${ }^{5}$ y la venta combinad $a^{6}$. Mientras que este último tipo de ventas combinadas o "en paquetes" sí que es permitido, en general se prohíben las ventas vinculadas (salvo en determinadas excepciones, como por ejemplo, la cuenta de ahorro necesaria para el servicio de capital e interés de un préstamo.

Por otro lado, también se regula tanto la información básica general que se habrá de proporcionar al consumidor sobre los contratos de crédito ofertados por el prestamista, como el contenido homogéneo para todos los EEMM de la información precontractual a través de una ficha europea de información normalizada (ver Cuadro 4).

Por último, también se incluye la provisión de explicaciones adecuadas al consumidor sobre el contrato de crédito propuesto para que pueda valorar si este se adapta a sus necesidades y a su situación financiera. Las explicaciones se harán sobre la información precontractual; las características esenciales del préstamo; los efectos que tendrá sobre el consumidor (especialmente el impago); otros productos complementarios contratados y en particular la posibilidad e implicaciones de rescindir de estos productos de forma separada.

\section{d) Tasa anual equivalente}

Se regula la fórmula de la nueva TAE europea común, que está basada en la información sobre el coste total del crédito e incluye todos los costes que el consumidor ha de pagar en relación al contrato de crédito que va a firmar y que son conocidos por el prestamista - los intereses, comisiones, impuestos, valoración del inmueble (siempre que dicha valoración sea necesaria para obtener el crédito) y otro tipo de gastos excepto los costes notariales.

${ }^{5}$ Prácticas de venta vinculada (definición Comisión Europea): toda oferta o venta de un paquete constituido por un contrato de crédito y otros productos o servicios financieros diferenciados, cuando el contrato de crédito no se ofrezca al consumidor por separado.

${ }^{6}$ Prácticas de venta combinada (definición Comisión Europea): toda oferta o venta de un paquete constituido por un contrato de crédito y otros productos o servicios financieros diferenciados, cuando el contrato de crédito se ofrezca también al consumidor por separado, aunque no necesariamente en los mismos términos y condiciones que combinado con otros servicios auxiliares 


\section{CUADRO 4 \\ ELEMENTOS CLAVES DE LOS NUEVOS REQUISITOS DE INFORMACIÓN EN LA UE SOBRE CRÉDITOS}

\begin{tabular}{|c|c|}
\hline Información general & Información precontractual \\
\hline $\begin{array}{c}\text { Información sobre los contratos de crédito que } \\
\text { ofrece el prestamista }\end{array}$ & $\begin{array}{c}\text { Información personalizada necesaria para } \\
\text { comparar créditos, valorar implicaciones y } \\
\text { tomar decisión formada }\end{array}$ \\
\hline $\begin{array}{l}\text { Información sobre productos (contenido } \\
\text { mínimo): } \\
\text { Identidad de quién emite la información. } \\
\text { Fines del crédito. } \\
\text { Tipo de garantía. } \\
\text { Duración posible del contrato. } \\
\text { Tipos de crédito (tipo deudor variable, fijo...). } \\
\text { Moneda. } \\
\text { Ejemplos sobre las cantidades a pagar: importe } \\
\text { del crédito, coste total, TAE. } \\
\text { Otros gastos a pagar en relación con el contrato } \\
\text { de préstamo. } \\
\text { Métodos de reembolso. } \\
\text { Condiciones para el reembolso anticipado. } \\
\text { Necesidad de tasación y costes. } \\
\text { Servicios accesorios necesarios y su coste. } \\
\text { Advertencias sobre incumplimiento. }\end{array}$ & $\begin{array}{l}\text { Entrega de la ficha europea de información } \\
\text { normalizada (FEIN, en sus siglas en español): } \\
\text { Su entrega, una vez aportada la información del } \\
\text { consumidor, se hace sin demora y con suficiente } \\
\text { antelación respecto a la celebración del contrato } \\
\text { (no se regulan tiempos). } \\
\text { En caso de que el consumidor reciba una oferta } \\
\text { vinculante (opcional), está deberá ir acompañada } \\
\text { de la FEIN en caso de no haberse proporcionado } \\
\text { con anterioridad o cuando las características } \\
\text { de la oferta vinculante sean diferentes a las } \\
\text { recogidas en la FEIN facilitada previamente. } \\
\text { El consumidor dispone de } 7 \text { días como mínimo } \\
\text { para comparar ofertas, valorar sus implicaciones } \\
\text { y tomar una decisión. Este plazo puede ser } \\
\text { previsto como: } \\
\text { - Un periodo de reflexión antes de la celebración } \\
\text { del contrato; } \\
\text { - Un periodo para el desistimiento tras la cele- } \\
\text { bración del contrato; } \\
\text { - Ambos. } \\
\text { Si es un periodo de reflexión, la FEIN deberá } \\
\text { ser vinculante para el prestamista (oferta vin- } \\
\text { culante). } \\
\text { La FEIN no puede ser modificada por los EEMM. } \\
\text { Cualquier información adicional debe incluirse } \\
\text { aparte. La CE puede adoptar actos delegados } \\
\text { para incluir información sobre nuevos productos } \\
\text { que aparezcan en el mercado, pero sin cambiar } \\
\text { la estructura de la FEIN. }\end{array}$ \\
\hline
\end{tabular}




\section{e) Evaluación de la solvencia}

Como principal medida para «asegurar» el endeudamiento responsable, se incluye la obligación de realizar un análisis de la solvencia del prestatario, en el que se tendrán en cuenta todos los factores relevantes que sirvan para verificar las perspectivas de que el consumidor cumplirá con sus obligaciones. No se permite que este análisis pueda depender predominantemente del valor del inmueble en garantía que exceda de la cantidad de crédito concedida, ni de la asunción de revalorización del primero ${ }^{7}$.

El crédito solo se concederá al consumidor cuando la evaluación de la solvencia indique que las obligaciones del contrato se podrán cumplir de la manera establecida. Cuando se deniegue una operación, se informará al consumidor sin demora.

\section{f) Tasación de los bienes inmuebles}

Se solicita a los EEMM el establecimiento de normas fiables para la tasación de bienes inmuebles de uso residencial a efectos del crédito hipotecario (a cumplir por las entidades o personas que realizan la tasación), y que aseguren que los tasadores internos o externos son profesionalmente competentes y suficientemente independientes del proceso de concesión para realizar tasaciones objetivas e imparciales.

\section{g) Préstamos con determinados riesgos}

Se recogen disposiciones concretas relacionados con los préstamos denominados en moneda extranjera (además de las advertencias sobre los riesgos, se habrá de incluir en los contratos el derecho de conversión de moneda) y los préstamos a tipo de interés variable (uso de índices de referencia claros, objetivos, accesibles y verificables; y registro de éstos).

\section{h) Ejecución de los contratos}

La Directiva incluye disposiciones legales sobre diversas materias relacionadas con la ejecución de los contratos. En primer lugar, se incluye regulación armonizada en materia de reembolso anticipado. Se garantiza como un derecho, aunque su ejercicio podrá estar sujeto a determinadas condiciones, que pueden ser o bien

${ }^{7}$ A menos que la finalidad del contrato sea la construcción o renovación del bien inmueble de uso residencial. 
limitaciones al momento del tiempo en el que se ejerce o bien restricciones sobre las circunstancias bajo las cuales se ejerce.

En este sentido, se reconoce el derecho por parte del prestamista a solicitar una compensación justa y objetiva por los costes incurridos, que no podrá exceder la pérdida financiera sufrida por el prestamista, y que no será una penalización (sino compensación). Los EEMM podrán disponer que la compensación no exceda de un nivel determinado o se autorice solo durante un determinado periodo de tiempo. Y en caso de que el reembolso anticipado quiera ejercerse en el transcurso de un periodo a tipo fijo, los EEMM además podrán prever que éste solo se realice en caso de existencia de interés legítimo por parte del consumidor.

En segundo lugar, se introducen medidas para tener mercados flexibles y fiables, consistentes en fomentar el uso de los registros de la propiedad, así como de la construcción de encuestas, índices y otros indicadores que ayuden al control del mercado.

En tercer lugar, se introducen reglas sobre las demoras y las ejecuciones hipotecarias, cuyos objetivos son los siguientes:

- Garantizar la tolerancia o paciencia del prestamista a la hora de iniciar procedimientos.

- Impedir la fijación de recargos o tasas moratorias que excedan de lo necesario para compensar los costes en los que incurre el prestamista.

- Eliminar cualquier obstáculo a que las partes de un contrato de crédito pacten en el inicio que la responsabilidad del deudor se limite únicamente a la vivienda en garantía.

- Promover que los EEMM adopten medidas que faciliten el reembolso en aquellos casos en que la deuda no quede saldada al término de un procedimiento de ejecución, con el fin de proteger al consumidor.

\subsection{Directrices de la Autoridad Bancaria Europea}

Antes de entrar a valorar el impacto de esta Directiva en los mercados nacionales, conviene resaltar que tras su publicación, ya hay aspectos de la norma que han sido abordados -y por tanto desarrollados con mayor detalle- por la EBA.

En este sentido, la EBA publicó el pasado mes de junio de 2015 la Directriz sobre retrasos y ejecuciones (EBA/GL/2015/12) y la Directriz sobre el análisis de la capacidad de pago (EBA/GL/2015/11). Apoyándose en que, en ambas áreas, la Directiva de crédito hipotecario recoge disposiciones muy generales, la EBA ha elaborado estas Directrices para asegurar que ambas disposiciones se implementan y se supervisan de forma consistente entre los EEMM, y así apoyar el proceso de trasposición de la Directiva. 
Cabe mencionar que la Directiva -en su artículo 18- requiere que los EEMM velen por que, antes de celebrar un contrato de crédito, el prestamista evalúe en profundad la solvencia del consumidor, teniendo en cuenta los factores pertinentes para verificar las perspectivas de cumplimiento por el consumidor de sus obligaciones. Dicha evaluación deberá realizarse basándose en la necesaria información, suficiente y proporcionada, sobre los ingresos y gastos y a otras circunstancias financieras y económicas del consumidor (artículo 20). Por otro lado, la Directiva, en su artículo 28, también requiere que los EEMM adopten medidas para alentar a los prestamistas a mostrarse razonablemente tolerantes antes de iniciar un proceso de ejecución.

Ambas directrices van dirigidas a las Autoridades competentes (en nuestro caso, Banco de España y Tesoro Público), quienes no están legalmente obligados a aplicarlas, pero que se espera hagan un esfuerzo por cumplirlas, y si no es así, argumenten el por qué. Su entrada en vigor no se producirá hasta el 21 de marzo de 2016, fecha límite para la trasposición de dicha norma.

En cuanto a su contenido, hay que destacar que ambas directrices desarrollan e imponen nuevos requerimientos de información a los prestamistas que no se contemplan en la Directiva y que, por tanto, probablemente deban tenerse en cuenta a la hora de trasponer la norma europea a nivel nacional.

\subsection{Impacto en los mercados hipotecarios}

El impacto de esta Directiva en los mercados hipotecarios europeos será, sin duda, significativo en la medida en que modifica sustancialmente los procesos de concesión de los préstamos hipotecarios.

No serán pocos lo países que tendrán que introducir cambios sustanciales en sus legislaciones, pues la nueva Directiva no solo incorpora nuevo contenido en la fase de la información, sino también nuevos procesos y tiempos hasta la firma final del contrato. No obstante, los cambios podrán ser más o menos profundos, dependiendo de lo más o menos intervencionista que haya sido la regulación de cada mercado.

A modo de ejemplo, una medida como «universalizar» el derecho de amortización anticipada, que apenas tendría efecto en nuestro mercado nacional por estar vigente desde la creación del propio mercado, puede suponer un gran cambio en un mercado hipotecario como el alemán, donde el prepago siempre ha sido una opción que podía ejercerse en determinados momentos y con coste (lo que permitía tener un riesgo de refinanciación muy bajo, ideal para la emisión de sus pfandbriefe).

Por otro lado, habrá cambios obligados en todos los países dado que hay muchas nuevas materias a incorporar en los marcos nacionales: la nueva ficha de información personalizada; el diseño de una nueva TAE europea, la regulación de las ventas vinculadas, o la introducción de exigencias de capacitación del personal dedicado a la comercialización hipotecaria (salvo para el caso inglés).

El impacto de todas estas medidas en cada mercado nacional dependerá de diversos factores, entre los que podemos destacar los siguientes: 
- En primer lugar y más importante, de cómo cada Autoridad nacional trasponga las disposiciones de la Directiva. Siempre que se cumplan con los mínimos, el grado de flexibilidad de los reguladores para ir más allá del cumplimiento literal de una norma es enorme. En este sentido, es muy probable que cada Estado aproveche esta oportunidad para actualizar muchas de sus disposiciones en la materia y/o incluir otras nuevas.

- En segundo lugar, los recientes desarrollos ocurridos en cada mercado hipotecario dictarán el tono de las normas aprobadas, y por tanto la laxitud o rectitud del enfoque adoptado. Algo que, aunque lógico, no deja de ir en contra de uno de los principios deseados por la regulación europea: «mismas reglas para todos».

- Además, como consecuencia de las diferentes estructuras legales y económicas de cada mercado, habrá casos donde el impacto de las medidas sobre las características de la oferta de productos hipotecarios sea más relevante.

\section{Caso español}

El impacto de implementar la Directiva en el mercado español debería ser bastante leve, en la medida en que desde el año 2011 muchos de los asuntos que recoge la norma europea ya se anticiparon e incluyeron en nuestra regulación actual ${ }^{8}$.

Del conjunto de materias de la Directiva, las áreas con una regulación nacional muy similar y que por tanto, se verán sometidas a modificaciones legales menores son:

- obligación de realizar un análisis de solvencia del consumidor;

- suministro de explicaciones adecuadas;

- regulación de una TAE común que refleje el coste total del crédito;

- nuevas disposiciones en relación a la tasación;

- regulación del derecho de reembolso anticipado;

- previsiones sobre la ejecución hipotecaria y demoras de los contratos.

Quizás algunos de los cambios más importantes para el mercado español sean los que se produzcan en los formatos de las actuales fichas de información precontractual y personalizadas, no solo por su contenido -pues habrá que incorporar una información adicional bastante exhaustiva en materia de TAE relacionada con la información sobre su composición y su cálculo; y un mayor detalle sobre las posibilidades de variación de la cuota, ya sea por la contratación de un préstamo a tipo de interés variable o con una moneda distinta a la nacional-, sino también por su estructura, que deberá variar para adaptarse a la ficha europea de información

\footnotetext{
8 Orden de transparencia EHA/2899/2011.
} 
normalizada. Igualmente, será necesario incorporar en el ordenamiento nacional la nueva información prevista por la norma europea para la publicidad de los productos de las entidades de crédito.

Por otro lado, habrá algunas materias que sí deban dotarse de una nueva regulación nacional, como por ejemplo:

- Las nuevas disposiciones europeas sobre venta vinculada y venta combinada o en «paquetes»;

- El establecimiento de nuevos requisitos legales para la remuneración y formación del personal.

Por tanto, la financiación -mediante hipoteca- a la vivienda en nuestro país se verá, sin duda, afectada por todos estos requerimientos. De forma positiva, se puede afirmar que el prestatario hipotecario estará más protegido en materia de información y transparencia en el proceso de contratación. De forma negativa, la operativa de formalización de un préstamo tenderá a alagarse y a ser más costosa, ya que los nuevos procedimientos que incorporan tanto la norma europea como las directrices de la EBA pueden burocratizar en exceso el día a día de las entidades, dificultando la actividad crediticia.

\section{Conclusiones}

No cabe duda de que estamos ante un momento de nueva y abundante regulación sobre el sector financiero, y con una nueva normativa europea sobre los créditos hipotecarios. La coincidencia en el tiempo de todos estos cambios va a tener indudables impactos en la actividad bancaria y en sus clientes.

Las nuevas normas en materia de requerimientos de capital y liquidez introducen medidas que, aun considerando los beneficios claros que tendrán para el mercado en términos de estabilidad financiera, inmovilizan más recursos y penalizan o restringen determinadas actividades, lo que puede acabar dificultando o encareciendo el crédito.

Por otro lado, tanto la nueva Directiva de crédito hipotecario como las directrices de la Autoridad Bancaria Europea sobre retrasos y ejecuciones, y también sobre el análisis de la capacidad de pago del prestatario, introducen nuevos procedimientos dentro de las entidades financieras, que tendrán que ser justificados y supervisados, lo que podría burocratizar en exceso el día a día de las entidades, dificultando la actividad crediticia.

Aunque el mercado hipotecario español no debería ser de los más afectados -al menos con respecto al impacto de medidas tales como la introducción de la ratio de apalancamiento, el requerimiento de financiación estable o la regulación en materia 
de amortización anticipada, tasación o las demoras y ejecuciones- sí preocupa el efecto acumulado que a lo largo del tiempo tendrán los siguientes cambios:

- La necesidad de aumentar el capital; y especialmente la posibilidad de endurecer los criterios preferenciales aplicados al crédito hipotecario.

- La obligación de aumentar los requerimientos de liquidez.

- Los mayores requisitos de información que se exigirán en los procesos de concesión de créditos.

- Una burocratización excesiva de los procesos de concesión y comercialización del crédito hipotecario.

Probablemente, todos estos posibles impactos no puedan valorarse hasta transcurrido un tiempo desde su implementación, que en muchos casos será gradual y en diferentes calendarios.

Además, algunos desarrollos a nivel nacional -como la modificación de la Ley Hipotecaria y de la Ley de Enjuiciamiento Civil en materia de ejecuciones hipotecarias, o la introducción de medidas especiales de protección del deudor hipotecario- también incidirán en la cantidad y características de la actividad hipotecaria futura, y por ello son factores adicionales que deben tenerse en cuenta en cualquier análisis para el caso de España del impacto de las nuevas y abundantes normas que a partir de ahora regularán la financiación hipotecaria.

\section{Referencias bibliográficas}

[1] ORDEN EHA/2899/2011, de 28 de octubre, de transparencia y protección del cliente de servicios bancarios.

[2] REGLAMENTO (UE) No. 575/2013 DEL PARLAMENTO EUROPEO Y DEL CONSEJO sobre los requisitos prudenciales de las entidades de crédito y las empresas de inversión, y por el que se modifica el Reglamento (UE) no 648/2012 (26 de junio de 2013).

[3] DIRECTIVA 2013/36/UE DEL PARLAMENTO EUROPEO Y DEL CONSEJO relativa al acceso a la actividad de las entidades de crédito y a la supervisión prudencial de las entidades de crédito y las empresas de inversión, por la que se modifica la Directiva 2002/87/CE y se derogan las Directivas 2006/48/CE y 2006/49/CE (26 de junio de 2013).

[4] IBÁÑEZ SANDOVAL, J. P. y DOMINGO ORTUÑO, B. (2013). «La transposición de Basilea III a la legislación europea». Revista de Estabilidad Financiera, núm. 25.

[5] COMITÉ DE SUPERVISIÓN BANCARIA DE BASILEA (2014). Basilea III: Marco del coeficiente de apalancamiento y sus requisitos de divulgación.

[6] DIRECTIVA 2014/17/UE DEL PARLAMENTO EUROPEO Y DEL CONSEJO sobre los contratos de crédito celebrados con los consumidores para bienes inmuebles de uso residencial y por la que se modifican las Directivas 2008/48/CE y 2013/36/UE y el Reglamento (UE) no 1093/2010 (4 de febrero de 2014). 
[7] ANALISTAS FINANCIEROS INTERNACIONALES (2015). «Titulaciones y cédulas en la cobertura de la liquidez (ratio LCR)». Nota Bancaria.

[8] DIRECTRIZ de la Autoridad Bancaria Europea sobre retrasos y ejecuciones (EBA/ GL/2015/12).

[9] DIRECTRIZ de la Autoridad Bancaria Europea sobre el análisis de la capacidad de pago (EBA/GL/2015/11) 
